\title{
The Little Red River Cree Nation's forest management strategies under a changing forest policy
}

\author{
by E. Krcmar ${ }^{1}$, G.C. van Kooten², H. Nelson ${ }^{3}$, I. Vertinsky ${ }^{4}$ and J. Webb ${ }^{5}$
}

\begin{abstract}
In this study, we explore alternative strategies available to the Little Red River Cree Nation for meeting their projected socio-economic needs using the natural resources to which they have access. We analyze outcomes from mathematical programming models for various forest policy regimes, ranging from current sustained-yield management to sustainable forest management. The potential outcomes of the two approaches are analyzed using financial returns, harvest volumes and ecological impacts. Results indicate that decision-makers face significant trade-offs in determining an appropriate management strategy for the forest lands they control. Our main conclusion is that economic development strategies for First Nations must diversify away from forest resources in the long run if they are to be successful.
\end{abstract}

Key words: boreal forest, First Nations, forest co-management, forest policy, old growth, sustainability

\section{RÉSUMÉ}

Cette étude nous a permis d'explorer les diverses stratégies se présentant à la Little Red River Cree Nation leur permettant de répondre aux besoins sociaux économiques envisagés par l'utilisation des ressources naturelles auxquelles elle a accès. Nous avons analysé les résultats des modèles mathématiques de programmation pour différents régimes de politiques forestières, allant de l'aménagement à rendement soutenu actuel à l'aménagement forestier durable. Les retombées potentielles de ces deux approches sont analysées sous l'angle du rendement financier, des volumes récoltés et des impacts environnementaux. Les résultats indiquent que les personnes qui prennent les décisions font face à des choix significatifs au moment de déterminer une stratégie appropriée d'aménagement pour le territoire forestier sous leur contrôle. Notre principale conclusion est que les stratégies de développement économique des Premières Nations doivent s'éloigner des ressources forestières à long terme si elles veulent être une réussite.

Mots clés : forêt boréale, Premières Nations, co-gestion forestière, politique forestière, vieille forêt, durabilité

\section{Introduction}

The economic prosperity and well-being of First Nations' communities requires development strategies that sustain traditional values. Since more than $80 \%$ of First Nations' communities in Canada are located in forested areas, it is not surprising that forest resources are seen as a source of livelihood that can be relied on to promote development and First Nations' goals of greater self-reliance (Natural Resources Canada 2001, Ross and Smith 2002). At the same time, forests provide environmental amenities and non-timber outputs that are an important source of cultural and spiritual values (Parsons and Preston 2003).

Provincial governments own more than $90 \%$ of forest resources in BC, Alberta, Ontario and Quebec, but they allocate much of the timber harvests on public (Crown) land to multinational timber companies under long-term leases that require the construction and operation of processing facilities. First Nations lack the capital and expertise to take on such tenure obligations, while prevailing legislation frequently provides native communities with no formal role in the management of forest resources (Ross and Smith 2002). Forest lands on Indian Reserves plus any other forest lands controlled by First Nations (e.g., forest land gained from the resolution of one of many extant land claims) are too small to permit self-sufficiency through forest development. Onreserve forests may, nonetheless, provide a starting point for building technical capacity and developing partnerships (e.g., through co-management agreements over Crown forests) as First Nations pursue goals of increased economic self-reliance (Treseder and Krogman 1999, Natcher and Hickey 2002).

The focus in this paper is on the Little Red River Cree Nation (LRRCN) in northern Alberta. This First Nation is pursuing economic development through a partnership with the Alberta Government and several forest companies in the region. In Alberta, the forest tenure system consists of areabased forest management agreements (FMAs) and volumebased timber quotas linked to specific forest management units (FMUs). By signing co-management agreements with

\footnotetext{
${ }^{1}$ Forest Economics and Policy Analysis (FEPA) Research Unit, University of British Columbia, 2424 Main Mall, Vancouver, British Columbia V6T 1Z4. E-mail: ekrcmar@interchange.ubc.ca

${ }^{2}$ Department of Economics, University of Victoria, PO Box 1700 STN CSC, Victoria, British Columbia V8W 2Y2. E-mail: kooten@uvic.ca ${ }^{3}$ Forest Economics and Policy Analysis (FEPA) Research Unit, University of British Columbia, 2424 Main Mall, Vancouver, British Columbia V6T 1Z4. E-mail: harrywn@interchange.ubc.ca

${ }^{4}$ Forest Economics and Policy Analysis (FEPA) Research Unit, University of British Columbia, 2424 Main Mall, Vancouver, British Columbia V6T 1Z4. E-mail: Ilan.Vertinsky@ sauder.ubc.ca

${ }^{5}$ Corporate \& Intergovernmental Relations, Little Red River Cree Nation, PO Box 30, John D’Or Prairie, Alberta T0H 3X0. E-mail: jwebb@incentre.net
} 
the Alberta government and the companies holding FMA tenures, LRRCN obtained timber quota on certain FMUs. This partnership is regarded as the leading example of how First Nations can become involved in resource development and management (NAFA and IOG 2000).

Alberta forest policy involves sustained yield management that focuses on continuity of harvest and forest growth, although in the long run these two concepts converge (Luckert and Williamson 2005). Implementation of the sustained yield policy usually involves maximization of the cumulative harvest, while maintaining an even flow of harvests over the planning horizon. The policy requiring evenflow harvests flies in the face of uncertainty regarding growth and yield, natural disturbances (fire, disease and insect infestations), price volatility, climate change, and even shifts in the forest policies themselves. Therefore, in addition to an evenflow requirement, we explore alternative strategies available to the LRRCN for meeting their goals, and examine timber and ecological outcomes under varying forest policies. All other factors affecting outcomes of forest management growth and yield, natural disturbances, product prices and climate change - are assumed to be given and known in advance.

We assume that the goal of the LRRCN is to develop and implement a forest management strategy that will ensure the community's economic sustainability, while preserving forest landscape features critical to on-going traditional-use of the forest and cultural values (Natcher and Hickey 2002). We begin by examining the current sustained-yield, timberfocused management strategy for forests under LRRCN tenure, but then contrast it with an alternative forest management strategy that addresses both socio-economic and ecological sustainability. The two approaches are analyzed in terms of their financial returns, harvest volumes, and environmental impacts, but they are evaluated in terms of how well each meets the objectives of the LRRCN.

The paper is organized as follows. The next section provides background information about the LRRCN and describes the objectives of the study in greater detail. The two sections thereafter present the methodology, namely, descriptions of the alternative management scenarios and the mathematical programming models. This is followed by an analysis of model outcomes for several management scenarios. We conclude with an evaluation and discussion of possible LRRCN development strategies.

\section{Study Objectives}

The LRRCN peoples have historically occupied portions of the Lower Peace River region in north-central Alberta and used these lands to support their culture and livelihood. Treaty No. 8 (1899) affirmed the right of the First Nation to use the resources within its historical area to sustain traditional vocations and way of life. LRRCN now has its own forest management company, Little Red River Forestry (LRRF), and a company holding timber quota that can be sold to forest companies (Askee Development Corporation). In 1995, the LRRCN and neighbouring Tall Cree First Nation entered into a cooperative management planning agreement with the Alberta Government and Tolko Industries Ltd. (Department of Aboriginal Affairs 1996). In addition to the agreements with Tolko, a volume agreement was later signed between LRRCN and Footner Forest Products Ltd. (Department of Aboriginal Affairs 1999) to supply deciduous fibre to an oriented strand board (OSB) mill. Under these agreements, the companies compensate LRRF for the costs of harvesting and reforestation (although only coniferous stands are replanted as deciduous stands are left to regenerate naturally). As the quota holder for LRRCN, Askee Development Corporation also receives stumpage fees for harvested timber, with payments linked to product prices in a manner similar to that used by the Alberta Government to establish stumpage rates. However, the Alberta Government also collects stumpage on volumes harvested under these tenures so the First Nation cannot collect all of the resource rent.

Our analysis focuses only on forest management unit F23 for which comprehensive timber resource information is available (see Fig. 1). The current strategy employed by the LRRF to manage F23 was designed to satisfy the objectives of the co-management agreements between LRRCN, the forest industry and the government (Department of Aboriginal Affairs 1996, 1999). In the current analysis, we consider the potential impacts of changing from the current sustainedyield forest policy to one based on sustainable management (differences are described in the next section), and examine alternative strategies available to the LRRCN for adapting to these changes and meeting their objectives. Specifically, our objectives are to assess the capacity of the forest landbase to provide for the needs of the LRRCN, and to evaluate the tradeoffs resulting from different management scenarios.

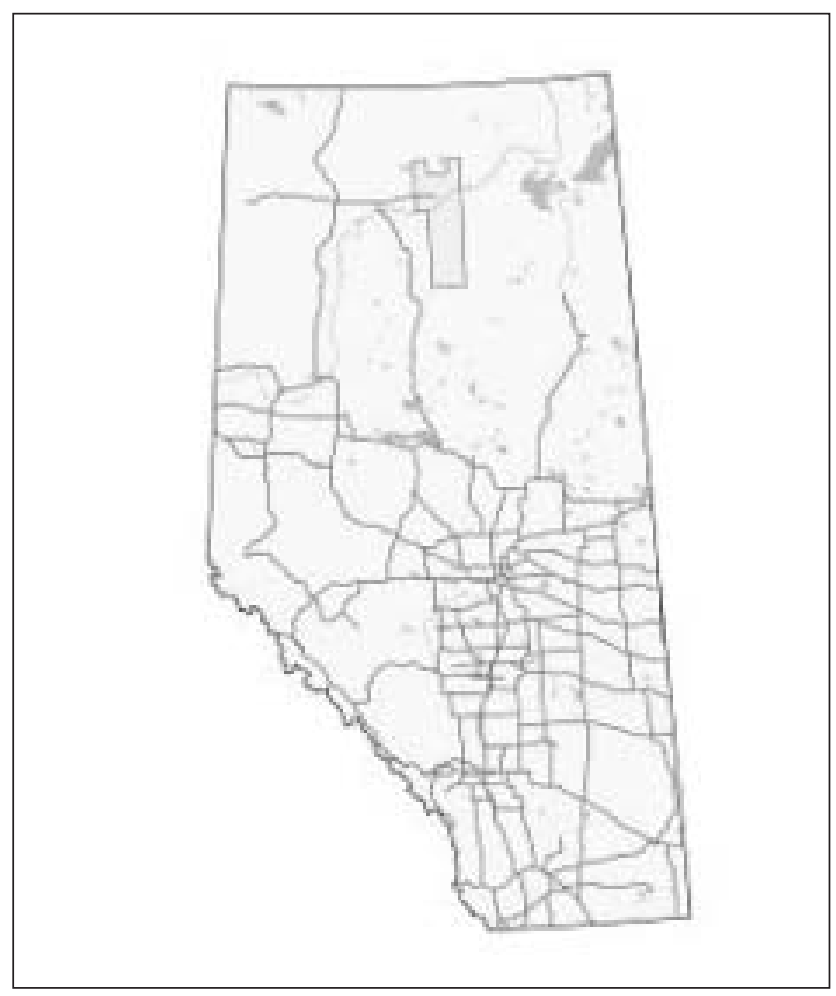

Fig. 1. The study area F23 relative to the Province of Alberta (Source: Timberline 2001a) 


\section{Management Scenarios}

Sustained-yield management emphasizes timber values and maintenance of harvest flows, while sustainable forest management shifts the focus to multiple forest values such as biodiversity, wildlife habitat, soil and water quality, and carbon uptake and storage. Alberta continues to employ sustainedyield forest management, although policy is being redesigned to take into account the natural dynamics of ecosystems natural disturbances (ASRD 2000). Researchers argue that sustainable forest management should mimic certain key characteristics of landscapes originating from disturbances such as fires (Perera et al. 2004), including the age distribution of stands, the distribution of stand type and size, and the shape and spatial arrangement of patches across the landscape (Bergeron et al. 1999). Old growth is a special consideration because of its contribution to the maintenance of biodiversity (Spies and Franklin 1996, Burton et al. 1999). In addition to their ecological significance, old-growth forests are an integral part of First Nations' beliefs: "The value First Nations people place on old-growth forests often reflects the fact that old growth is crucial to their continued existence. Old growth is inextricably bound to the culture of First Nations and this fact has to be recognized in management decisions, as there is simply no replacement for old-growth forest for many aspects of First Nations culture" (Walkem 1994).

In this paper, we choose conservation of old growth over time as a proxy for sustainable forest management policy. Preservation of specified amounts of old growth is seen as an initial step in the implementation of a strategy that focuses on natural disturbances (Angelstam 1998, Schneider 2002). Hence, we examine policy scenarios that differ by requirements imposed on both minimum proportions of old growth and flows of harvest volume over the planning horizon. Under sustainable forest management, there are two general approaches for defining targets on old growth preservation: One is to calculate the expected proportion of old growth based on the annual incidence of fire, while the other is to utilize the pattern present in the existing forest. For the sustainable management scenarios, we determine the old growth targets using the latter approach. The initial proportions of old coniferous and deciduous forests are $31.3 \%$ and $8.2 \%$, respectively (see Appendix, Table A1), where old growth is defined as forests older than 100 years. Based on the initial inventory patterns, we set the targets for preserving old coniferous and deciduous forests at $30 \%$ and $8 \%$ of their respective harvest areas.

The harvest flow requirements address concerns related to adequate timber supply for mills, and thereby jobs and community stability. Scenario 1 requires maintaining non-declining coniferous and deciduous harvest flows over time. Although no preservation of old growth over time is required, the end-period inventory must have a minimum $10 \%$ old growth. This constraint prevents complete depletion of forest resources at the end of the planning horizon. We refer to this strategy as "sustained-yield management." Scenario 2 includes an additional requirement to preserve a minimum amount of old growth over time, in addition to maintaining non-declining harvest flows. This scenario is referred to as "sustainable management with strict harvest flow con-
Table 1. Alternative Management Scenarios

\begin{tabular}{llcc}
\hline & & \multicolumn{2}{c}{$\begin{array}{c}\text { Minimum } \\
\text { Old Growth (\%) }\end{array}$} \\
\hline Scenario & Harvest flow & Coniferous & Deciduous \\
\hline 1. SYM & non-declining & none & none \\
2. SFM - strict flow & non-declining & 30 & 8 \\
3. SFM - lax flow & variations up to 10\% & 30 & 8 \\
\hline
\end{tabular}

a Requirement on the amount of old forest over time expressed as a portion of the coniferous and deciduous harvest landbase.

straints." Scenario 3 is a variation of scenario 2, obtained by relaxing the non-declining harvest flow constraint and allowing variability in both deciduous and coniferous harvests between planning periods. We refer to this scenario as "sustainable management with lax harvest flow constraints." The three management scenarios - (1) sustained yield management, (2) sustainable management with strict harvest flow constraints, and (3) sustainable management with lax harvest flow constraints - are summarized in Table 1.

\section{Mathematical Programming Models}

To examine the ability of local timber resources to support a stable and sustainable economic base for the local First Nations' communities under different forest policies, we first formulate models for long-term strategic forest planning over the period 2000 to 2200 . The 200 -year planning period is chosen according to strategic planning practices used in Alberta to ensure that sustainability conditions are truly satisfied (ASRD 1996). The dynamic character of the models takes into account the effect that current decisions have on the future state of the forest and available future management options. The study region, inventory, yield and economic data are discussed in detail in Appendix A.

We formulate models that determine harvest schedules to maximize cumulative discounted net returns of timber benefits over the planning horizon, while maintaining alternative flows of harvest volume and preserving a minimum amount of old growth by forest type over time. The 200-year planning horizon is divided into twenty decades. Harvest scheduling decisions are addressed in a non-spatial manner using linear programming. Our models follow the classic land allocation and harvest scheduling problems over large temporal and spatial scales (Davis and Johnson 2001).

The model elements are defined as follows. Forest characteristics are aggregated into management strata, where a stratum $m$ is defined as a combination of tree species, density, height and age. Let $M$ denote the set of management strata and $T$ the number of planning periods. In addition, let $M_{g} \subset M, g \in G=\{$ conif, decid $\}$ represent a partition of $M$ by the coniferous and deciduous forest types $g$. We also introduce a set $M_{g}^{O G} \subset M$ that contains old growth strata of type $g$. The index-sets $M_{g}$ and $M_{g}^{O G}$ allow us to address constraints and objectives specific to old growth, and coniferous and deciduous forest types.

A decision variable $x_{m, t}$ denotes area (ha) of stratum $m$ harvested in period $t$. Denote by $v_{m, t}$ merchantable volume 
$\left(\mathrm{m}^{3} / \mathrm{ha}\right)$ from a hectare of stratum $m$ harvested in period $t$ and by $n_{m}$ net revenue per cubic meter $\left(\$ / \mathrm{m}^{3}\right)$ of timber from stratum $m$. Let $A_{g}$ be the area (ha) of forest type $g$ available for harvest, $\operatorname{Val}(x)=\sum_{s, t} v_{m, x}, x_{m}$, the harvest volume $\left(\mathrm{m}^{3}\right)$ of type
gin period $t$ and $O G_{r},(x)-\sum_{n=V_{t}} x_{m, t}$ the area (ha) of old forest of type $g$ in
period $t$.

Allowable variation in harvest flow between periods is defined as a specific proportion of the volume harvested in a planning period. We set up the harvest flow constraints (eq. 3 ) and (eq. 4) on a 20-year period basis since the volume quota in Alberta are usually negotiated over that period. The conservation requirements are expressed in terms of a proportion of old growth relative to the total harvest area by forest type. A parameter $\alpha_{g, t}$ denotes the maximum allowable variation of harvest flow between periods $t$ and $t+2$, and $\omega_{g, t}$ denotes the minimum portion of old growth of type $g$ in period $t$. The discount rate is denoted by $\rho$. Using this notation, we formulate the problem as an LP:

$$
\begin{aligned}
& \text { Model (P) } \\
& \text { Maximize [1] } N(x)=\sum_{m=1} \sum_{t=1}^{r}(1+\rho)^{5-1 N} n_{n} v_{m, t}, x_{m, t} \\
& \text { subject to: [2] } O G_{v, t}(x) \geq a t_{x, r} A_{n} \quad t \geq t_{1} \\
& \text { [3] } \operatorname{Vol}_{x, x+1}(x)=\operatorname{Vol}_{f,}(x) \quad t=1,3, \ldots \ldots, T-1 \\
& \text { [4] }\left|\operatorname{Vol}_{s+1+2}(x)-\operatorname{Vol}_{s, r}(x)\right| \leq \alpha_{s, 1} \operatorname{Vol}_{s, i}(x) \text {, } \\
& t=1,3, \ldots, T-2 \\
& \text { [5] } x_{m, 1} \geq 0
\end{aligned}
$$

Objective function $N(x)$ is discounted net revenue from timber benefits. In objective [1], we assume that harvesting takes place mid-period and is discounted accordingly. Constraint [2] is used to preserve old growth - the righthand side $\left(\omega_{g, t} A_{g}\right)$ is the minimum proportion of net harvested landbase of type $g$ to be preserved in old growth conditions in period $t$. Constraints [3] and [4] are stable flow of timber requirements, with $\alpha_{g, t} V o l_{g, t}(x)$ an upper bound on allowable fluctuations of harvest volume of type $g$ in period $t+2$ relative to harvest volume in period $t$. Equation [5] is the non-negativity constraint on the decision variables. The linear program $P$ is solved using CPLEX on the GAMS platform (Brooke et al. 1998).

\section{Outcomes for Management Scenarios}

In this section, we examine (1) the impact of different old growth requirements on fibre flow over time, (2) the impact of even-flow harvests on the distribution of old growth over time, and (3) measures to maintain economically viable forestry in the region while preserving old growth characteristics of the landscape.

\section{Timber-related outcomes}

Model outcomes in terms of total volume by forest type and discounted total stumpage revenue under different manage-

\begin{tabular}{|c|c|c|c|}
\hline \multirow[t]{2}{*}{ Scenario } & \multicolumn{2}{|c|}{ Cumulative Harvest (mil. $\mathrm{m}^{3}$ ) } & \multirow[t]{2}{*}{$\begin{array}{l}\text { Discounted } \\
\text { Net Revenue } \\
\quad \text { (\$ mil. })\end{array}$} \\
\hline & Coniferous & Deciduous & \\
\hline 1. SYM & 72.839 & 77.071 & 48.025 \\
\hline 2. SFM - strict flow & 67.207 & 70.723 & 44.250 \\
\hline 3. SFM - lax flow & 61.779 & 69.744 & 51.337 \\
\hline
\end{tabular}
ment scenarios are provided in Table 2. Several results are highlighted. The total volumes delivered over time depend both on the requirements imposed on minimum amounts of old growth and harvest flows. Cumulative harvest volumes
Table 2. Cumulative Harvest Volumes and Discounted Net Revenue.

under scenarios 2 and 3 are lower by $8 \%$ and $12.3 \%$ than the respective volumes generated under the benchmark scenario 1. By requiring that a minimum amount of old-growth forest be preserved over time, cumulative harvest volume drops significantly relative to the unconstrained case in scenario 1 . A departure from the even-flow harvest regime leads to only a $4.6 \%$ reduction of the harvest volume under scenario 3 relative to scenario 2 .

Cumulative harvests decline substantially under a stricter requirement to conserve old-growth forest and are reduced even further under harvest flow constraints. A stricter policy for preserving old forest over time has similar effects on net revenue reduction; it reduces total discounted net revenue under the SFM-lax flow scenario by $7.9 \%$ relative to its benchmark value under the SYM regime. Surprisingly, revenue under the SFM-lax flow regime of $\$ 51.337$ million is higher by $6.9 \%$ than the revenue under the SYM scenario. The SFM-lax flow scenario revenue is higher by $16 \%$ than that under the SFM-strict flow scenario. Thus, higher financial benefits are possible even when stronger conservation requirements are imposed, but the way to achieve better financial returns is to permit higher variations in harvests between one period and the next.

Average annual harvests (based on cumulative harvests) are an important indicator of a stable fibre supply to the processing facilities. The requirement for preserving a certain proportion of the landbase in old growth coupled with an even-flow harvest requirement reduces average harvest flow for scenario 2 relative to the benchmark scenario 1 . Under scenario 2, annual coniferous and deciduous harvests drop by $7.7 \%$ and $8.2 \%$, respectively. Under the SFM with lax flow regime (Scenario 3 ), the average annual coniferous and deciduous harvests drop by $15.2 \%$ and $12.3 \%$, respectively, relative to the annual harvests under the benchmark SYM scenario. Under the sustainable management with lax flow regime (Scenario 3), annual coniferous volumes fluctuate between $242703 \mathrm{~m}^{3}$ and $405137 \mathrm{~m}^{3}$ (Fig. 2a). The range of annual deciduous harvest is even wider, fluctuating from $278935 \mathrm{~m}^{3}$ and $456854 \mathrm{~m}^{3}$ (Fig. 2b).

\section{Ecological outcomes}

When analyzing LRRCN development strategies, it is necessary to balance the financial and timber volume outcomes of each scenario against the corresponding ecological impacts. But ecological impacts are difficult to measure because forest management affects many forest characteristics. Mimicking natural disturbance patterns, especially those related to wildfire, is considered an important alternative forest policy in Alberta (Adamowicz and Veeman 1998). Since such natural 


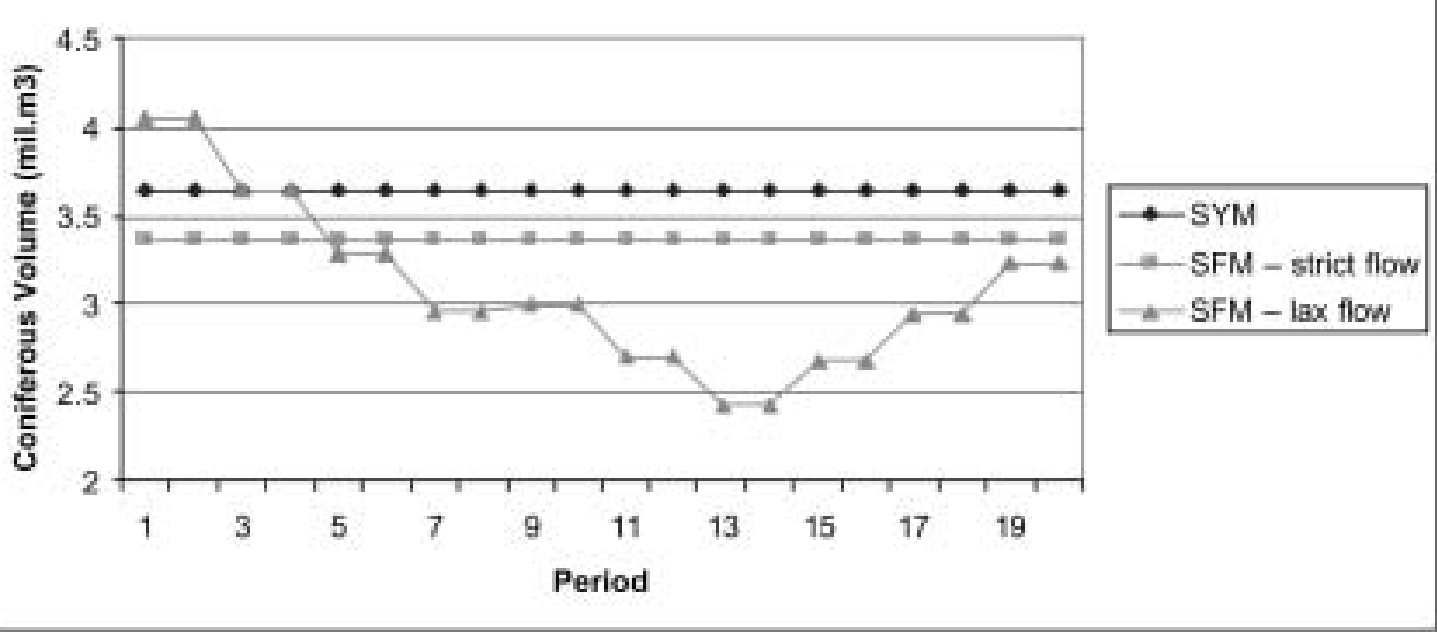

(a)

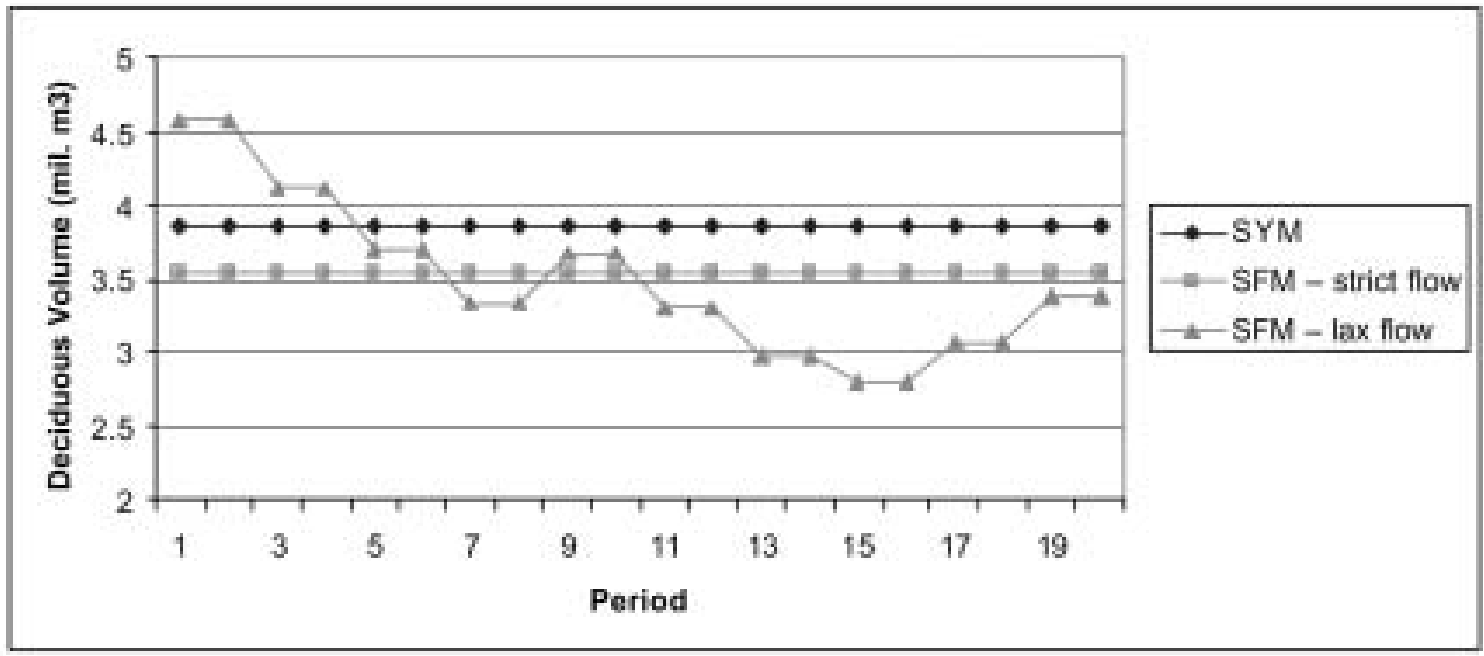

(b)

Fig. 2. Temporal distribution of the (a) coniferous and (b) deciduous harvest volumes, by management scenario.

disturbances greatly impact the age distribution of the forest (Wallenius 2002), we use the distribution of old forest over time as a proxy for the ecological impacts.

For each of the three scenarios, the distribution of old forest over time is projected (Fig. 3). The relative amount of old coniferous forest increases during the initial 40 to 50 years, but decreases steeply thereafter (Fig. 3a). About mid-horizon, the relative amount of old coniferous forest falls below $20 \%$, and, for the last 50 years of the horizon, it drops below $10 \%$. Such a pattern of coniferous old growth over time may have negative ecological and economic impacts, as it does not support future forest diversity or sustainable wood production. The temporal distribution of deciduous old growth differs slightly from the coniferous case. The relative amount of old deciduous forest reaches its peak in period 4 (year 40) and continues to decline for the next 40 years (Fig. 3b). For the remaining 120 years, the relative amount of deciduous old growth fluctuates between $2 \%$ and $11 \%$.

The previous analysis of the age distribution of standing inventory under the SYM regime reveals an alarming pattern, especially regarding the distribution of coniferous old growth in the latter half of planning horizon. These patterns signal a need to change forest policy to protect old growth in managed forests. Sustainable management scenarios 2 and 3 require preservation of certain amounts of old growth over time. Outcomes of the two scenarios in terms of the temporal distribution of old growth are presented in Fig. 3.

Old growth constraints imposed under the SFM regimes bind the coniferous and deciduous old growth starting with periods 8 and 9, respectively (Fig. $3 \mathrm{a}$ and $3 \mathrm{~b}$, scenarios 2 and 3 ). This can only be achieved, however, by keeping a significant portion of the landbase (almost 50\%) in old growth condi- 


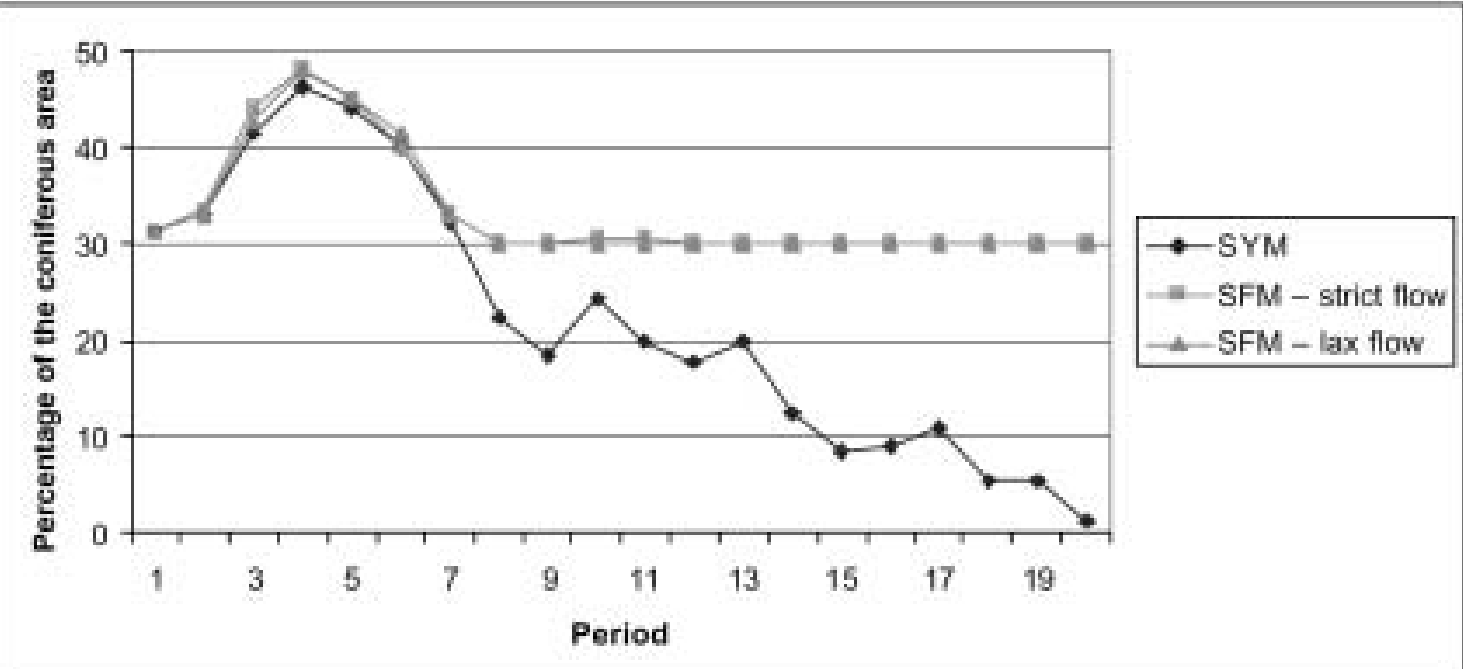

(a)

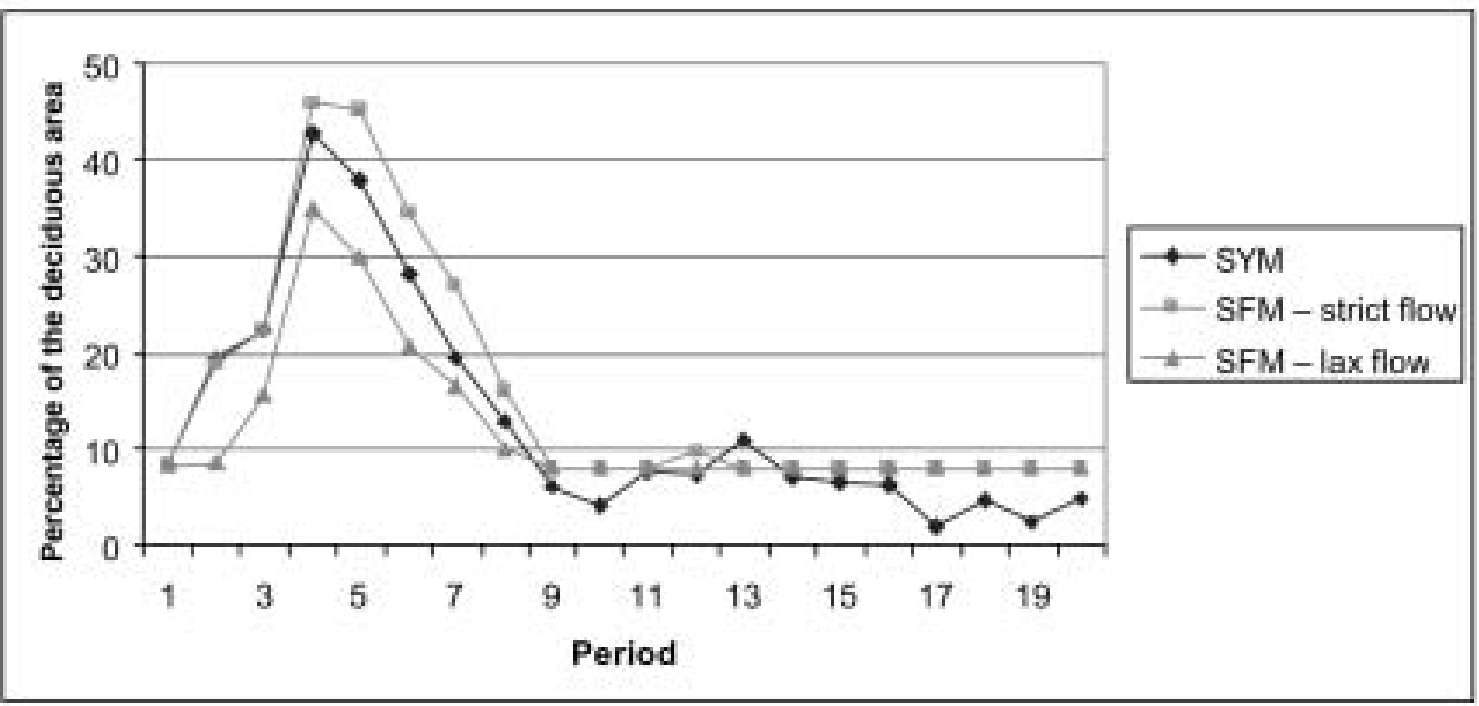

(b)

Fig. 3. Temporal distribution of the (a) coniferous and (b) deciduous old growth as a percent [\%] of the respective harvest area, by management scenario.

tions during periods 4 and 5 . Note that the latter pattern also emerges in scenario 1, despite the lack of any requirement on old growth conservation over the horizon in that scenario. This outcome is a consequence of the initial inventory age structure, which is dominated by mature forest (see Fig. A1).

\section{Evaluating Alternative Strategies for the First Nation}

When selecting among potential development strategies, LRRCN faces trade-offs among four aspects: (1) total timber volume available to mills in the long term; (2) total discounted revenues generated over the planning horizon (wealth generated); (3) the time path associated with different management regimes (community stability); and (4) forest age structure (ecological concerns). LRRCN development objectives include capacity building as the basis for economic self-sufficiency and eventual self governance, while preserving ecological, cultural and spiritual values.

Consider the outcomes of even-flow yield management as a benchmark to which the two sustainable management strategies are to be compared. As indicated in the previous section, the even-flow yield strategy produces a stable supply of both coniferous and deciduous timber that could be used to support a primary wood processing facility (an option desired by LRRCN). However, the even-flow yield strategy is not without a number of associated costs. It leads to depletion of the forest resource, with about $75 \%$ of the landbase in an early succession stage by the end of the planning horizon. Because of ecological concerns and associated non-timber 
values, decision-makers have already been asked by community members to preserve additional wildlife habitat within the harvest landbase. Further, relatively lower financial returns associated with the even-flow yield strategy do not provide economic surpluses that can be used to fund economic development in other areas.

The sustainable management with the lax harvest flow regime (scenario 3 ) offers an opportunity for greater financial returns at the beginning of the planning horizon. A strategy generated under scenario 3 that relies on intensive harvest activities at the beginning of the horizon may enable LRRCN to achieve high financial returns without sacrificing future use of forest resources. These returns could be diverted for building technical and professional capacity to be used by current and future generations. By virtue of the imposed age distribution conditions on standing inventory, the sustainable management strategies ensure that forest resources will keep providing benefits to future generations. But these scenarios also result in declining harvest volumes relative to the even-flow yield strategy. Therefore, none of the management strategies considered (in which we utilize both the existing sustained-yield management regime and consider alternative approaches incorporating sustainability) is able to meet all LRRCN objectives. What approach, then, can LRRCN take?

\section{Discussion}

Canadian governments have traditionally relied on the exploitation of forest resources under sustained yield or evenflow policies that focus on harvesting and processing to generate economic activity. This approach has been criticized for not recognizing the increasing importance of other uses of forest resources and non-timber values (Binkley 2000, Howlett and Rayner 2001). Our results support the view that even-flow policies are inadequate as a driver of economic development. Further, the levels of even-flow timber will likely be inadequate for development of major secondary manufacturing facilities.

If timber availability could be enhanced, positive employment gains could be achieved by moving from simple supply of logging and forest services (current LRRCN employment) into the manufacturing of wood products. Pursuing such a strategy involves a significant financial investment in infrastructure and the education and training of employees, and investments in the provision of a stable future supply of fibre.

We examined sustainable management scenarios that mimic the forest age distribution achieved as a result of natural disturbance (mainly fire). Although we did not do so, the model permits the inclusion of additional constraints on preservation of wildlife habitat and structural diversity within the harvest landbase. It is likely that, if new ecological constraints are introduced, financial and timber volume outputs may well be reduced. The same is true if there is an increase in natural disturbances, such as forest fires and insect outbreaks (perhaps the result of climate change). Given that the existing timber management regime is unlikely to satisfy LRRCN objectives, and that placing greater emphasis on ecological sustainability is likely to further reduce economic opportunities (given existing economic conditions and human capital within the communities), LRRCN may face unpalatable tradeoffs among these options unless they are able to develop alternative strategies that avoid these tradeoffs. But this, too, requires investment in either additional resources outside the community or in the capacity of community members at the same time that LRRCN faces a host of pressing social needs.

The results of the modeling exercise must be interpreted cautiously because they depend on a variety of assumptions that may not hold in practice. Natural disturbances due to fire and insect infestations, and uncertainty related to forest growth (perhaps due to climate change) and economic parameters such as output prices, are inherently unpredictable over a 200 -year planning horizon. Further, actual harvest schedules and corresponding outcomes are directly dependent on the old growth targets. The targets for old growth preservation in our sustainable forest management scenarios were set conservatively using the relative amount of coniferous and deciduous old growth in the initial year 2000 inventory. Since the amount of old growth in boreal forests depends on the rate of disturbance, an alternative approach is to set targets by calculating the expected proportion of old growth based on the annual incidence of fire. For the 1960-2000 and 1980-2000 periods, annual incidences of fire recorded in northern Alberta were $0.4 \%$ and $0.63 \%$, respectively (Schneider 2002, Table 8.2). Using $0.4 \%$ and $1 \%$ annual incidence of fire, the expected percentages of coniferous and deciduous old growth are $67 \%$ and $37 \%$, respectively (Bergeron et al. 1999, Schneider 2002). The model outcomes in terms of the cumulative net revenue and harvest flow over time would be significantly lower if the latter old growth targets were used in our sustainable management scenarios.

The general conclusion of this paper, regardless of the targets used, is that LRRCN needs to prepare for a fibre shortfall in the second half of this century. Thus, the LRRCN's longterm development strategy should not be based on forest resources only. Rather, the First Nation needs a development strategy that spreads the risks of relying on forestry only. Although this is true of all forest-dependent communities, it is more important for First Nations because of the limited number of development options that are compatible with their traditional values and way of life.

\section{Acknowledgements}

The authors wish to acknowledge research support from the Sustainable Forest Management Network. Subject to the usual qualifier, we also thank Geordie Robere-McGugan of Timberline Forest Inventory Consultants for generously helping us acquire data, and Tim Gauthier and Dave Cole of Little Red River Forestry and Darryl Price of Alberta Environment for providing additional information and clarification.

\section{References}

Adamowicz, W. and T. Veeman. 1998. Forest policy and the environment: Changing paradigms. Canadian Public Policy XXIV: S51-S61. Angelstam, P.K. 1998. Maintaining and restoring biodiversity in European boreal forests by developing natural disturbance regimes. Journal of Vegetation Science 9: 593-602.

Alberta Sustainable Resource Development (ASRD). 1996. Sustained Yield In Alberta. Available at http://www3.gov.ab.ca/srd/ forests/fmd/timber/Sustained.htm.

Alberta Sustainable Resource Development (ASRD). 2000. Alberta's Implementation Action Plan for the National Forest Strategy (1998-2003). Progress Report to April 2000. Available at http://www. srd.gov.ab.ca/forests/fmd/nfs/pdf/nfsap2000.pdf. 
Alberta Sustainable Resource Development (ASRD). 2005. Crown Timber-Timber Dues for Coniferous and Deciduous Products. Available at http://www.srd.gov.ab.ca/forests/fmd/directives/currdues.html.

Bergeron, Y., B. Harvey, A. Leduc and S. Gauthier. 1999. Forest management guidelines based on natural disturbance dynamics: stand and forest-level considerations. The Forestry Chronicle 75: 49-54.

Binkley, C. 2000. A crossroad in the forest. In D. Salazar and D. Alper (eds.). Sustaining the Forests of the Pacific Coast. pp. 174-192. UBC Press, Vancouver.

Brooke, A., D. Kendrick, A. Meeraus and R. Raman. 1998. GAMS. A User's Guide. GAMS Development Corporation, Washington, DC. Burton, P., D. Kneeshaw and D. Coates. 1999. Managing forest harvesting to maintain old growth in boreal and sub-boreal forests. The Forestry Chronicle 75: 623-631.

Davis, L.S. and K.N. Johnson 2001. Forest Management. 4th edition. McGraw-Hill Book Company, New York, NY.

Howlett, M. and J. Rayner. 2001. The Business and Government Nexus: Principal Elements and Dynamics of the Canadian Forest Policy Regime. In M. Howlett (ed.). Canadian Forest Policy. pp. 23-64. University of Toronto, Toronto, ON.

Luckert, M.K. and T. Williamson. 2005. Should sustained yield be part of sustainable forest management? Canadian Journal of Forest Research 35: 356-364.

Department of Aboriginal Affairs. 1996. Little Red River Cree Nation - Tall Cree Nation and the Government of Alberta Cooperative Management Agreement. Edmonton, AB.

Department of Aboriginal Affairs. 1999. Little Red River Cree Nation - Tall Cree Nation and the Government of Alberta Cooperative Management Agreement. Edmonton, AB.

National Aboriginal Forestry Association and Institute on Governance (NAFA and IOG). 2000. Aboriginal-Forest Sector Partnerships: Lessons for Future Collaboration. June. 85 p. Available at http://www.nafaforestry.org/nafaiog/index.php.

Natcher, D.C. and C.G. Hickey. 2002. A criteria and indicators approach to community development. Sustainable Forest Management Network. Working Paper 2002-2. Edmonton, AB.
Natural Resources Canada. 2001. First Nation Forestry Program: Five years in review 1996/97-2000/01. Ottawa., ON.

Parsons, R. and G. Preston. 2003. Aboriginal forestry in Canada. The Forestry Chronicle 79: 779-784.

Perera, A.H., L.J. Buse and M.G. Weber (eds.) 2004. Emulating Natural Forest Landscape Disturbances - Concepts and Applications. Columbia University Press, NY.

Ross, M. and P. Smith. 2002. Accommodation of Aboriginal rights: the need for an Aboriginal forest tenure (Synthesis Report). Sustainable Forest Management Network. Edmonton, AB.

Schneider, R.B. 2002. Alternative Futures: Alberta's Boreal Forest at the Crossroads. The Federation of Alberta Naturalists and the Alberta Centre for Boreal Research, Edmonton, AB. Available at http://www.borealcentre.ca/reports/reports.html

Spies, T.A. and J.F. Franklin. 1996. The diversity and maintenance of old-growth forests. In R.C. Szaro and D.W. Johnston (eds.). Biodiversity in Managed Landscapes. pp. 296-314. Oxford University Press, Oxford, UK.

Timberline Forest Inventory Consultants Ltd. 2001a. Landbase Determination - Forest Management Unit F23. Technical Report. Edmonton, $\mathrm{AB}$.

Timberline Forest Inventory Consultants Ltd. 2001b. Yield Curve Development - Forest Management Unit F23. (VERSION 2.1). Technical Report. Edmonton, AB.

Treseder, L. and N.T. Krogman. 1999. Features of First Nation forest management institutions and implications for sustainability. The Forestry Chronicle 75: 793-798.

Walkem, A. 1994. First Nations and Old Growth Values. Spence's Bridge, B.C. Cook's Ferry Band.

Wallenius, T. 2002. Forest age distribution and traces of past fires in a natural boreal landscape dominated by Picea abies. Silva Fennica 36: 201-211. 


\section{Appendix}

Our analysis focuses on FMU F23 for which comprehensive timber resource information is available. Timberline Forest Inventory Consultants Ltd. determined the net landbase currently available for timber harvesting within the management unit. Determination of the net harvesting landbase is founded on the current Alberta Timber Harvest Planning and Operating Ground Rules and applicable land-base exclusions (Timberline 2001a). The forest inventory was determined from the approved Alberta Vegetation Inventory (AVI version 2.1). To incorporate First Nations' requirements for forest management that is compatible with traditional land use and values, particular types of forest land are excluded from the harvest landbase. Harvesting is prohibited on First Nations' reserves, protected areas, cultural areas, and special places and natural areas. The LRRCN also acknowledges the need to integrate wildlife values into forest management plans. Wildlife habitat areas are excluded from the harvesting landbase. Further, excluded from the landbase are forest areas where stands are inoperable or isolated and exclusions based on operating ground rules. The timber harvesting landbase covers 384603 ha or 39\% of the F23 area, divided into 15 classes for which timber yield data are available (Timberline 2001a, b). The forest resource within the region is made up of two predominant species - white spruce and aspen.

The age distribution of the starting inventory is shown in Fig. A1. The starting inventory refers to the landbase available for timber harvesting in 2000 . We contrast the age distribution of the coniferous harvest landbase to that of the deciduous landbase (see Table A1). A feature of the starting inventory is the large area of both coniferous and deciduous forest in the 60 - to 100 -year age classes $(63.4 \%$ of the harvesting landbase). This spike in the age class distribution is characteristic of previous disturbance regimes. Compared to the proportion of young coniferous stands (22.3\%), a smaller pro-
Table A1. Age Class Distribution of Initial Inventory

\begin{tabular}{lccc}
\hline & \multicolumn{3}{c}{ Portion of harvest landbase $(\%)$} \\
\hline $\begin{array}{c}\text { Young } \\
(\mathfrak{E} \text { 50 years })\end{array}$ & $\begin{array}{c}\text { Mature } \\
(50-100 \text { years })\end{array}$ & $\begin{array}{c}\text { Old growth } \\
(\geq 100 \text { years })\end{array}$ \\
Coniferous & 22.28 & 46.44 & 31.29 \\
Deciduous & 8.81 & 82.98 & 8.21 \\
Total & 16.01 & 63.43 & 20.55 \\
\hline
\end{tabular}

portion of young deciduous stands is present (only 8.8\%). About $14 \%$ of the coniferous harvestable landbase is in the earliest regeneration stage (10-year age class), with this high proportion attributable to the 1998 Mikkwa fire. On the other hand, the smaller proportion of deciduous old growth (8.21\%) reflects the fact that deciduous trees reach maturity and decay sooner than coniferous species, which also contributes to lower fire incidence.

As already noted, forest companies compensate LRRCN for the costs of harvesting and reforestation based on the 1996 and 1999 MOUs, plus a quota payment that is linked to product prices. To develop the net revenue function, we use Alberta historical stumpage rates for the softwood lumber and OSB, the two principal products currently manufactured from timber harvested under the tenure. Alberta stumpage rates are linked to market prices that fluctuate widely. Using available data (ASRD 2005), we calculated the average softwood lumber payment for 2001 to be $\$ 3.79 / \mathrm{m}^{3}$ and average OSB timber payment for 2001 to be $\$ 1.23 / \mathrm{m}^{3}$. As no specific price trend was noticeable, we use these figures in our calculation of the net revenue function. A 5\% real rate of discount was used to calculate the present value of stumpage revenue.

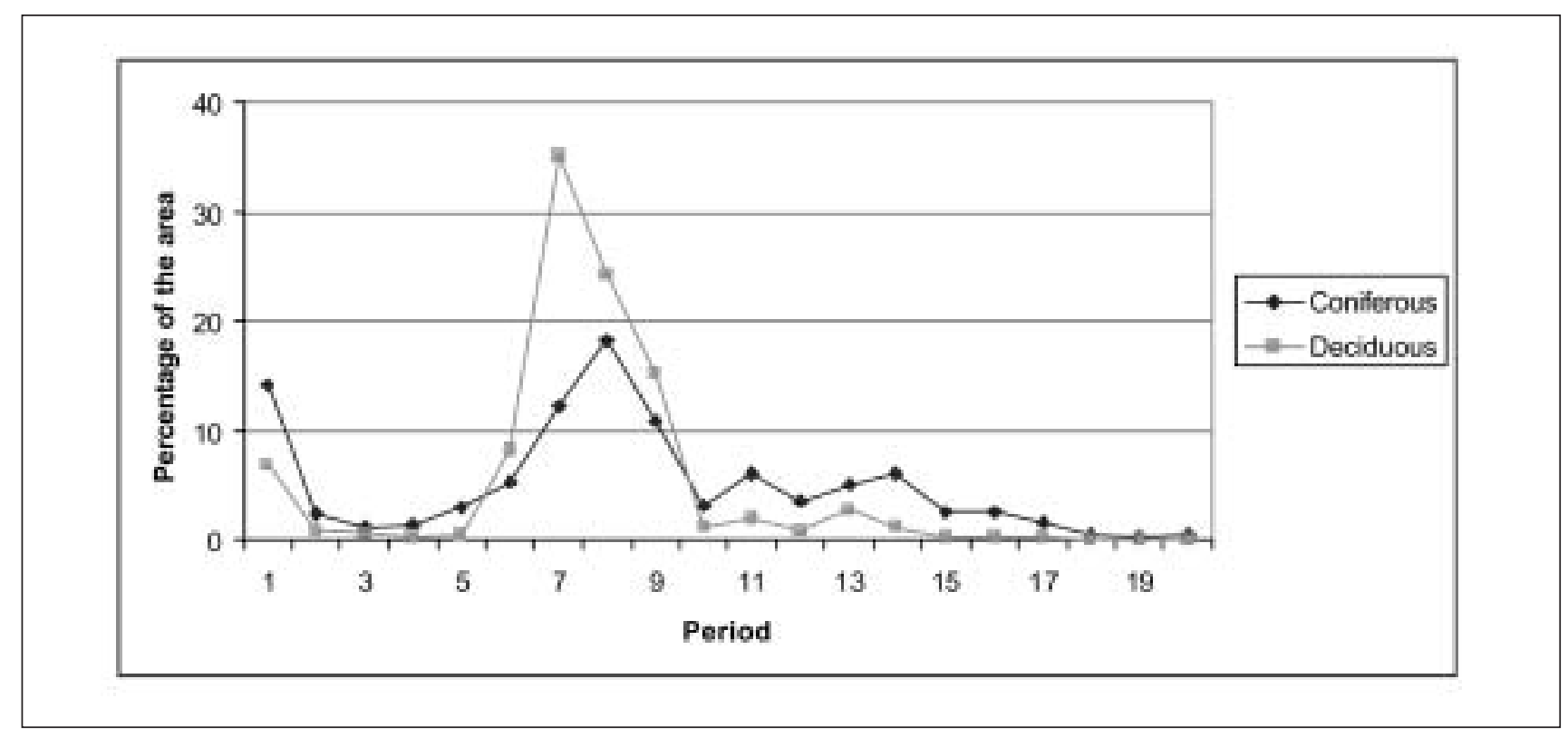

Fig. A1. Age distribution of the initial inventory as a percent [\%] of the coniferous and deciduous harvest landbase. 